OPEN ACCESS

Edited by:

Hongchen Jiang,

Miami University, USA

Reviewed by:

Bartosz Adamczyk,

University of Helsinki, Finland

Yuting Liang,

Institute of Soil Science (CAS), China

*Correspondence:

Charlotte J. Alster

charlotte.alster@colostate.edu

${ }^{\dagger}$ Present address:

Peter Baas,

Growcentia, Inc., Fort Collins, CO,

USA

Specialty section:

This article was submitted to Terrestrial Microbiology, a section of the journal

Frontiers in Microbiology

Received: 26 August 2016

Accepted: 28 October 2016

Published: 17 November 2016

Citation:

Alster CJ, Baas P, Wallenstein MD, Johnson NG and von Fischer JC (2016) Temperature Sensitivity as a Microbial Trait Using Parameters from Macromolecular Rate Theory.

Front. Microbiol. 7:1821

doi: 10.3389/fmicb.2016.01821

\section{Temperature Sensitivity as a Microbial Trait Using Parameters from Macromolecular Rate Theory}

\author{
Charlotte J. Alster ${ }^{1,2 *}$, Peter Baas ${ }^{3+}$, Matthew D. Wallenstein ${ }^{2,3,4}$, Nels G. Johnson ${ }^{5}$ and \\ Joseph C. von Fischer ${ }^{1,2}$
}

\begin{abstract}
'Department of Biology, Colorado State University, Fort Collins, CO, USA, ${ }^{2}$ Graduate Degree Program in Ecology, Colorado State University, Fort Collins, CO, USA, ${ }^{3}$ Natural Resource Ecology Laboratory, Colorado State University, Fort Collins, CO, USA, ${ }^{4}$ Department of Ecosystem Science and Sustainability, Colorado State University, Fort Collins, CO, USA, ${ }^{5}$ National Institute for Mathematical and Biological Synthesis, University of Tennessee, Knoxville, TN, USA
\end{abstract}

The activity of soil microbial extracellular enzymes is strongly controlled by temperature, yet the degree to which temperature sensitivity varies by microbe and enzyme type is unclear. Such information would allow soil microbial enzymes to be incorporated in a traits-based framework to improve prediction of ecosystem response to global change. If temperature sensitivity varies for specific soil enzymes, then determining the underlying causes of variation in temperature sensitivity of these enzymes will provide fundamental insights for predicting nutrient dynamics belowground. In this study, we characterized how both microbial taxonomic variation as well as substrate type affects temperature sensitivity. We measured $\beta$-glucosidase, leucine aminopeptidase, and phosphatase activities at six temperatures: $4,11,25,35,45$, and $60^{\circ} \mathrm{C}$, for seven different soil microbial isolates. To calculate temperature sensitivity, we employed two models, Arrhenius, which predicts an exponential increase in reaction rate with temperature, and Macromolecular Rate Theory (MMRT), which predicts rate to peak and then decline as temperature increases. We found MMRT provided a more accurate fit and allowed for more nuanced interpretation of temperature sensitivity in all of the enzyme $x$ isolate combinations tested. Our results revealed that both the enzyme type and soil isolate type explain variation in parameters associated with temperature sensitivity. Because we found temperature sensitivity to be an inherent and variable property of an enzyme, we argue that it can be incorporated as a microbial functional trait, but only when using the MMRT definition of temperature sensitivity. We show that the Arrhenius metrics of temperature sensitivity are overly sensitive to test conditions, with activation energy changing depending on the temperature range it was calculated within. Thus, we propose the use of the MMRT definition of temperature sensitivity for accurate interpretation of temperature sensitivity of soil microbial enzymes.

Keywords: macromolecular rate theory, MMRT, activation energy, Q10, temperature optimum, extracellular enzymes, microbial isolates, trait-based ecology 


\section{INTRODUCTION}

The activities of extracellular enzymes, a rate-limiting step in decomposition and important component in biogeochemical cycles (Burns and Dick, 2002), are strongly controlled by in situ temperatures (Davidson and Janssens, 2006; Wallenstein et al., 2011). Although the importance of enzyme temperature sensitivity is widely recognized, the degree to which temperature sensitivity is an inherent property of the enzymes vs. a response to environmental conditions (Davidson and Janssens, 2006) is largely unknown. It has been difficult to parse the mechanisms underlying observations of enzyme temperature responses in part because assays are typically conducted at the community level where the contribution of isoenzymes produced by individual taxa cannot be isolated (Bradford, 2013; Karhu et al., 2014). In addition, relative and absolute measures of temperature sensitivity using the same, simple models often produce contradictory results (Sierra, 2012). Understanding if these soil extracellular enzymes have inherent temperature sensitivity is critical for accurate predictions of soil carbon (C) and other nutrient dynamics in changing environments. In this study we attempt to determine the degree to which soil enzymes are responsive to temperature. In addition, we focus on clearing up some of the definitional confusions regarding temperature sensitivity in soils.

Over most of the last decade, the debate on if and how temperature sensitivity differs among enzymes has used parameters from two models: the $Q_{10}$ temperature coefficient and activation energy, $E_{\mathrm{A}}$, derived from the Arrhenius equation. $Q_{10}$ is a unitless measure of the change in rate with a 10-degree increase in temperature,

$$
Q_{10}=\left(\frac{R_{2}}{R_{1}}\right)^{10 /\left(T_{2}-T_{1}\right)}
$$

where $R$ is reaction rate and $T$ is temperature. The $Q_{10}$ of biological systems is generally thought to be $\sim 2$ or 3 , although it has been found to be substantially higher in some soils and enzymes (Lloyd and Taylor, 1994; Chapin and Matson, 2011; Elias et al., 2014). The Arrhenius equation describes temperature response as

$$
\operatorname{In}(k)=\operatorname{In}(A)-\frac{E_{A}}{R T},
$$

where $k$ is the reaction rate constant, $A$ is a pre-exponential factor, $E_{\mathrm{A}}$ is the activation energy, $R$ is the universal gas constant, and $T$ is temperature. According to the Arrhenius model, temperature sensitivity is compared using $E_{\mathrm{A}}$ as the parameter of interest instead of or in addition to $Q_{10}$. Reactions with higher $Q_{10}$ values require a larger "push" or activation energy $\left(E_{\mathrm{A}}\right)$ to initiate the reaction (Davidson and Janssens, 2006).

Previously, studies have drawn varying conclusions about how $Q_{10}$ and $E_{\mathrm{A}}$ vary with enzyme structure and function. From an evolutionary perspective, selection should generate an adaptive fit of enzyme kinetics to their thermal environment (Allison et al., 2011; Bradford, 2013). For example, thermophilic enzymes tend to have increased conformational rigidity (Zavodszky et al., 1998), while psychrophilic enzymes have improved flexibility, particularly at the active site (Feller, 2003; Struvay and Feller, 2012), impacting temperature sensitivity. Many soil studies have observed significant differences among $Q_{10}$ and $E_{\mathrm{A}}$ values at a range of spatial and temporal scales (Koch et al., 2007; TrasarCepeda et al., 2007; Wallenstein et al., 2009; Brzostek and Finzi, 2012; Steinweg et al., 2013). Despite the predicted and observed differences between these different types of enzymes and isoenzymes, an analysis conducted by (Elias et al., 2014) found no statistical difference across enzyme classes in $Q_{10}$ values from 150 enzymatic reactions.

One reason why patterns in $Q_{10}$ and $E_{\mathrm{A}}$ are not easily explained is that they may not be the most appropriate parameters to evaluate temperature sensitivity from soil microbial enzymes (Schipper et al., 2014). It has long been recognized that Arrhenius and $Q_{10}$ do not always accurately describe the relationship between temperature and reaction rates in soil systems (Lloyd and Taylor, 1994), yet they have continued to be used out of convenience, convention, or perhaps due to lack of a better alternative model. The most conspicuous disparity between these models is the empirical data commonly observed showing negative curvature (i.e., a concave-down parabolic response) in rate vs. temperature, which is not explained by either $Q_{10}$ or $E_{\mathrm{A}}$. This negative curvature is typically ascribed to enzyme denaturation even though the pattern is sometimes observed at relatively low temperatures. We hypothesize that this negative curvature causes estimated $Q_{10}$ and $E_{\mathrm{A}}$ values to vary with the temperature range where they are measured, thus making them more phenomenological parameters than fundamental system properties (Pawar et al., 2016). A second issue is that thermodynamic principles indicate that the Arrhenius models are missing a key term when applied in biological systems: for large macromolecules like enzymes, it is not appropriate to assume that the transition state of Gibbs Free Energy $\left(\Delta G^{\ddagger}\right)$ is constant across temperatures (Hobbs et al., 2013).

A relatively new model, Macromolecular Rate Theory (MMRT), accounts for both the physical and biological components of reaction rate with temperature (Hobbs et al., 2013). MMRT is defined as,

$$
\begin{aligned}
\operatorname{In}(k)= & \operatorname{In}\left(\frac{k_{\mathrm{B}} T}{h}\right)-\frac{\Delta H_{\mathrm{T} 0}^{\ddagger}+\Delta C_{\mathrm{p}}^{\ddagger}\left(T-T_{0}\right)}{R T} \\
& +\frac{\Delta S_{\mathrm{T}_{0}}^{\ddagger}+\Delta C_{\mathrm{p}}^{\ddagger}\left(\operatorname{In} T-\operatorname{In} T_{0}\right)}{R}
\end{aligned}
$$

where $k$ is the rate constant, $k_{B}$ is Boltzmann's constant, $h$ is Planck's constant, $R$ is the universal gas constant, $T$ is temperature, $H$ is enthalpy, $S$ is entropy, $C_{P}$ is heat capacity, and $\ddagger$ indicates that it is the transition state. Thus, we propose that the idea of "temperature sensitivity" when described by MMRT emerges as three fundamental components: the heat capacity of the enzyme $\left(\Delta C_{\mathrm{p}}^{\ddagger}\right)$, the temperature optimum $\left(T_{\text {opt }}\right)$, and the point of maximum temperature sensitivity $\left(\mathrm{TS}_{\max }\right)$. The heat capacity of the enzyme describes the degree of curvature in the parabolic response of reaction rate with temperature; more parabolic curves have larger, negative values of $\Delta C_{\mathrm{p}}^{\ddagger}$ that arise when enzymes are more rigid at the transition state. The 
temperature optima denote the point at which the reaction rate is greatest, with lower reaction rates at higher temperatures not necessarily indicating enzyme denaturation. The point of maximum temperature sensitivity is calculated from the first derivative of $k$ with temperature $(d k / d T)$, and indicates the temperature where the rate of change is greatest.

Our proposed concept of temperature sensitivity could enable use of traits-based approaches for understanding how community-level patterns in temperature sensitivity are related to thermal responses of the many isoenzymes produced by diverse microbes. Under this definition of temperature sensitivity, $\Delta C_{\mathrm{p}}^{\ddagger}, T_{\text {opt }}$, and $\mathrm{TS}_{\max }$ are measurable properties of individual organisms, or enzymes from organisms, and one that clearly would influence organismal performance, falling under the ecological definition of a functional trait (McGill et al., 2006). Including temperature sensitivity in a traits-based framework could enable the linking of the microbial community with soil ecosystem functioning (Green et al., 2008), as well as allow for a stronger quantitative approach to integrate temperature sensitivity into models for improved predictive power (Webb et al., 2010).

If temperature sensitivities of enzymes are in fact traits and exhibit variation based on genetic and environmental variation, we hypothesize that different enzymes will demonstrate distinct temperature sensitivities, as defined by the terms $\Delta C_{\mathrm{p}}^{\ddagger}, T_{\text {opt }}$, and $\mathrm{TS}_{\max }$. Because the difference in $\Delta C_{\mathrm{p}}^{\ddagger}$ is impacted by the physical flexibility of the enzyme (Hobbs et al., 2013), which we hypothesize is a result of genetic variation among communities and/or from interaction with substrate type, we predict that temperature sensitivity of soil extracellular enzymes will vary by the microbe from which the enzyme was derived or by the enzyme type. Because most enzymes are substrate specific, different enzyme-substrate complexes can have a wide range of $\Delta C_{\mathrm{p}}^{\ddagger}$ values. Moreover, different microbes produce different isoenzymes, so temperature sensitivity may also vary among microbes.

We measured extracellular enzyme activity from seven soil isolates and three different enzymes at six temperatures, in order to advance the study of temperature sensitivity as an intrinsic microbial trait. In a previous study (Alster et al., 2016), we found that temperature sensitivity varied among soil microbial communities. We applied both Arrhenius and MMRT to our data to compare the effectiveness of each of these models and demonstrate how Arrhenius estimates of temperature sensitivity may not be sufficient, even within in situ representative temperature ranges.

\section{MATERIALS AND METHODS}

\section{Experimental Design}

Extracellular enzymatic assays were performed for three enzymes, $\beta$-glucosidase (BG), leucine aminopeptidase (LAP), and phosphatase (PHOS) on seven soil isolates, each from a different genera-Acinetobacter, Bacillus, Citrobacter, Comamonas, Enterobacter, Flaviobacterium, and Pseudomonas. The isolates were derived either from soil or worm castings and kept at $-80^{\circ} \mathrm{C}$ with $20 \%$ glycerol until use. The isolates were revived from storage and grown in nutrient broth over a 2-3 days period at $25^{\circ} \mathrm{C}$. We added 3-( $N$-morpholino)propanesulfonic acid buffer to maintain a $\mathrm{pH}$ of 7.2 , which is the same $\mathrm{pH}$ as the microbes were originally isolated at. Before we began the enzyme assays, the isolate solution was plated on nutrient broth agar and total incubation time was determined by when cultures reached between $10^{5}-10^{7}$ colony-forming units per $\mathrm{mL}$.

The isolates were incubated in 96-well microplates with substrates at six temperatures: $4,11,25,35,45$, and $60^{\circ} \mathrm{C}$. We chose a large initial temperature range in order to capture the most accurate temperature response curve. The enzyme assay was modified from Bell et al. (2013). Forty microliters of $200 \mathrm{mM}$ fluorometric substrate-4-MUB- $\beta$-D-glucopyranoside for BG, Lleucine-7-amido-4-methylcoumarin hydrochloride for LAP, and 4-MUB phosphate for PHOS-was added to $160 \mu \mathrm{L}$ of a 1 isolate mixture: 15 acetate buffer solution. For each isolate $\times$ substrate combination, there were eight replicates for each temperature (7 isolates $\times 3$ enzymes $\times 6$ temperatures $\times 8$ replicates). Standards ranging from 2.5 to $100 \mu \mathrm{M}$ were used to calibrate the enzyme activity from each enzyme. 4-methylumbelliferone (MUB) was used to calibrate BG and PHOS and 7-amino-4-methylcoumarin (MUC) was used to calibrate LAP. The plates were incubated between 1 and $23 \mathrm{~h}$ depending on the temperature and scanned on a Tecan Infinite M200 plate reader at optimal florescence as determined by the MUB and MUC standards. Reaction rates were linear regardless of incubation time, as determined by preliminary experiments. The MUB and MUC standard curves were used to calculate the raw florescence of the samples using the slope and y-intercept, as described in Bell et al. (2013) and converted into units of nmol activity $\mathrm{L}_{\text {culture }}{ }^{-1}$ hour $^{-1}$, so that samples were comparable across temperatures with varying incubation times.

\section{Calculating Temperature Sensitivity}

In order to quantitatively characterize temperature responses of each of the 21 isolate $\times$ enzyme combinations, we plotted the natural $\log$ of the reaction rate against temperature and fitted both the Arrhenius and MMRT equations using an analytic Gauss-Newton for Arrhenius and a numerical Gauss-Newton for MMRT in JMP Pro 11 (Schipper et al., 2014; Alster et al., 2016). Parameters $E_{\mathrm{A}}$ and $\Delta C_{\mathrm{p}}^{\ddagger}$, along with their uncertainty, were reported by the software. The optimum temperature $\left(T_{\text {opt }}\right)$ and point of maximum temperature sensitivity $\left(\mathrm{TS}_{\max }\right)$ from the MMRT curve fits were calculated by taking the derivative of the MMRT equation with respect to temperature (Alster et al., 2016). We used a Monte Carlo Simulation to estimate the standard error for $T_{\text {opt }}$ and $\mathrm{TS}_{\max }$.

Analysis of variances (ANOVA) were performed using the software $\mathrm{R}$ version 3.2.1 ( $\mathrm{R}$ Core Team, 2015) to determine the relative importance of substrate type and species type in explaining variation in the parameters from each of the models $\left(\Delta C_{\mathrm{p}}^{\ddagger}, \Delta S_{T_{0}}^{\ddagger}, \Delta H_{T_{0}}^{\ddagger}, E_{\mathrm{A}}\right.$, and $\left.A\right)$ as well as for $T_{\text {opt }}$ and $\mathrm{TS}_{\max }$. We also used $\mathrm{R}$ to run pairwise comparisons with a Holm multiple testing adjustment to examine differences between each of the model parameters and $T_{\text {opt }}$ and $\mathrm{TS}_{\max }$ from each of 
the isolate $\times$ enzyme combinations. Differences in $\Delta C_{\mathrm{p}}{ }^{\ddagger}$ were calculated using a two-sampled approximate $Z$-test.

\section{Comparison of MMRT and Arrhenius Equations}

We used adjusted $R^{2}$ and Akaike information criterion corrected for a finite sample size (AICc) to determine the most parsimonious model between the Arrhenius and MMRT model fits for the full temperature range $\left(4-60^{\circ} \mathrm{C}\right)$. Additionally, we re-ran the Arrhenius model fit for each isolate $\times$ enzyme combination, but only using temperatures $4-25$ and $4-35^{\circ} \mathrm{C}$ to evaluate if, under more biologically relevant temperatures, the Arrhenius model fits were accurate predictors of reaction rate. To assess this, we calculated the percentage that each of the three models (MMRT from 4 to $60^{\circ} \mathrm{C}$, Arrhenius from 4 to $35^{\circ} \mathrm{C}$, and Arrhenius from 4 to $25^{\circ} \mathrm{C}$ ) over or underestimated the reaction rate as compared to the actual experimental values and conducted corresponding lack-of-fit (LOF) tests. The importance of each of these models for predicting the percent error was examined with a linear model and tested with an ANOVA using the lmerTest package in R (Kuznetsova et al., 2014).

\section{RESULTS}

\section{Temperature Sensitivity Differs for Isolate $\times$ Enzyme Combinations}

Out of the 21 isolate $\times$ enzyme combinations we tested, we present here the results from the 19 that worked. BG activity in Bacillus and PHOS activity in Comamonas were below detection limits. Thus, these two combinations were eliminated from the analysis. We plotted the reactions rates of the remaining 19 isolate $\times$ enzyme combinations vs. temperature and fit both the MMRT and Arrhenius equations to the data (Figure 1). These model fits for MMRT give temperature sensitivity parameters $\Delta C_{\mathrm{p}}^{\ddagger}, T_{\mathrm{opt}}$ and $\mathrm{TS}_{\mathrm{max}}$, while Arrhenius gives $E_{\mathrm{A}}$ as a parameter.

We found that $\Delta C_{\mathrm{p}}^{\ddagger}$ differed for some, but not all of the isolate $\times$ enzyme combinations. The $\Delta C_{\mathrm{p}}^{\neq}$differed among microbial isolates in BG and LAP enzymes $(P<0.05$; Figures 2A,B). However, in PHOS, the isolates did not differ in $\Delta C_{\mathrm{p}}^{\ddagger}(P>0.05$; Figure $2 \mathrm{C})$. When comparing if $\Delta C_{\mathrm{p}}^{\ddagger}$ differed between the same isolate for different enzymes we found significant differences in $\Delta C_{\mathrm{p}}^{\ddagger}$ for Acinetobacter, Citrobacter, and Enterobacter $(P<0.05)$, but not for Bacillus, Comamonas, Flaviobacterium, or Pseudomonas. Patterns in statistical differences were identical for $\Delta C_{\mathrm{p}}^{\ddagger}, \Delta S^{\ddagger}$, and $\Delta H^{\ddagger}$. Overall $70.9 \%$ of variation in $\Delta C_{\mathrm{p}}^{\ddagger}$ was explained by the microbial isolate type, compared with $29.1 \%$ of the variation explained by the enzyme type.

The temperature optima $\left(T_{\mathrm{opt}}\right)$ and point of maximum temperature sensitivity $\left(\mathrm{TS}_{\max }\right)$ also varied with the isolate $\times$ enzyme combinations (Table 1). Despite the $25^{\circ} \mathrm{C}$ conditions used during initial culturing of the inoculum isolates, $T_{\text {opt }}$ ranged from $33.5^{\circ} \mathrm{C}$ in $\mathrm{BG}$ for the Enterobacter isolate to $60.7^{\circ} \mathrm{C}$ in LAP for the Bacillus isolate and $\mathrm{TS}_{\max }$ ranged from $18.2^{\circ} \mathrm{C}$ in $\mathrm{BG}$ for the Acinetobacter isolate to $40.3^{\circ} \mathrm{C}$ in
LAP for the Bacillus isolate. Pooling the $T_{\mathrm{opt}}$ and $\mathrm{TS}_{\max }$ values across the same microbial isolate and enzyme type, we found differences for some of the values across both microbial isolate and enzyme type $(P<0.05)$. While differences between these pooled values for $T_{\text {opt }}$ and $\mathrm{TS}_{\max }$ were similar, they were not identical. Furthermore, similar to $\Delta C_{\mathrm{p}}^{\ddagger}$, variation in $T_{\mathrm{opt}}$ and $\mathrm{TS}_{\max }$ are best explained by the microbial isolate type, with SS values of 86.7 and $80.0 \%$, respectively.

The three metrics of temperature sensitivity, $\Delta C_{\mathrm{p}}^{\ddagger}, T_{\text {opt }}$ and $\mathrm{TS}_{\max }$, each have unique statistical patterns of similarity across inocula $\times$ enzyme combinations. In this paper, we do not deeply examine the basis for groupings but focus instead on identifying if patterns of similarity and difference exist or if all enzymes behave similarly. For conciseness, we illustrate only patterns of differences for $\Delta C_{\mathrm{p}}^{\ddagger}$ in Figure 2, and provide $T_{\mathrm{opt}}$ and $\mathrm{TS}_{\max }$ findings in Table 1. For PHOS we found no differences in $\Delta C_{\mathrm{p}}^{\ddagger}$ among the different microbial isolates (Figure 2). For $\mathrm{TS}_{\max }$ of PHOS there were no differences, but for $T_{\text {opt }}$ we found several significant differences among isolates (Table 1). Likewise for $\mathrm{BG}$, there were quite a few differences among isolates in $\Delta C_{\mathrm{p}}^{\ddagger}$ (Figure 2). However, there were no significant differences between different microbial isolates in $\mathrm{TS}_{\max }$ for $\mathrm{BG}$, and while there are differences in $T_{\text {opt }}$, they are not the same as the differences identified for $\Delta C_{\mathrm{p}}^{\ddagger}$. Interestingly, patterns in significant differences among isolates for LAP are the same for $T_{\text {opt }}$ and $\mathrm{TS}_{\mathrm{max}}$, but show a different pattern for $\Delta C_{\mathrm{p}}^{\ddagger}$. Some of these patterns likely emerge because $T_{\text {opt }}$ and $\mathrm{TS}_{\max }$ are positively correlated $\left(R^{2}=0.84\right)$, while $\Delta C_{\mathrm{p}}^{\ddagger}$ does not correlated with $T_{\mathrm{opt}}$ or $\mathrm{TS}_{\max }\left(R^{2}=0.23\right.$ and $R^{2}=0.01$, respectively).

\section{MMRT Provides Better Statistical Fit than Arrhenius}

For the temperature range of $4-60^{\circ} \mathrm{C}$, we found that MMRT gave vastly superior fits to the data as compared to Arrhenius according to both AICc and $\mathrm{R}^{2}$ criteria (Supplementary Table S1). MMRT was also superior when the Arrhenius model was fit to the more linear part of the temperature range $\left(4-35\right.$ and $\left.4-25^{\circ} \mathrm{C}\right)$ for 13 of the 19 isolate $\times$ enzyme combinations (see example, Figure 3A; Supplementary Table S1). For the six combinations where MMRT was not superior, AICc analysis found MMRT and Arrhenius to have equivalent explanatory power; in no case was Arrhenius the superior model. Phosphatase was the only enzyme where MMRT was significantly better in all isolates tested.

Despite the statistically improved fit of MMRT as compared to Arrhenius, when comparing the overall error produced from each of the model predictions, the results were less striking. We found $3.8 \%$ of the total variation was explained by LOF from the model in MMRT compared with $6.2 \%$ for Arrhenius from 4 to $35^{\circ} \mathrm{C}$ and $10.3 \%$ for Arrhenius from 4 to $25^{\circ} \mathrm{C}$. This means that by using Arrhenius instead of MMRT we are introducing 1.6 and 2.7 times more error into our predictions for the Arrhenius 4-35 and 4$25^{\circ} \mathrm{C}$ models, respectively. ANOVA results for the percent error of the models compared to the experimentally observed results at $4,11,25$, and $35^{\circ} \mathrm{C}$, revealed a significant difference between MMRT and the Arrhenius $4-25^{\circ} \mathrm{C}$ model $(P \leq 0.05)$ and between the two Arrhenius models $(P=0.02)$. However, there was no 

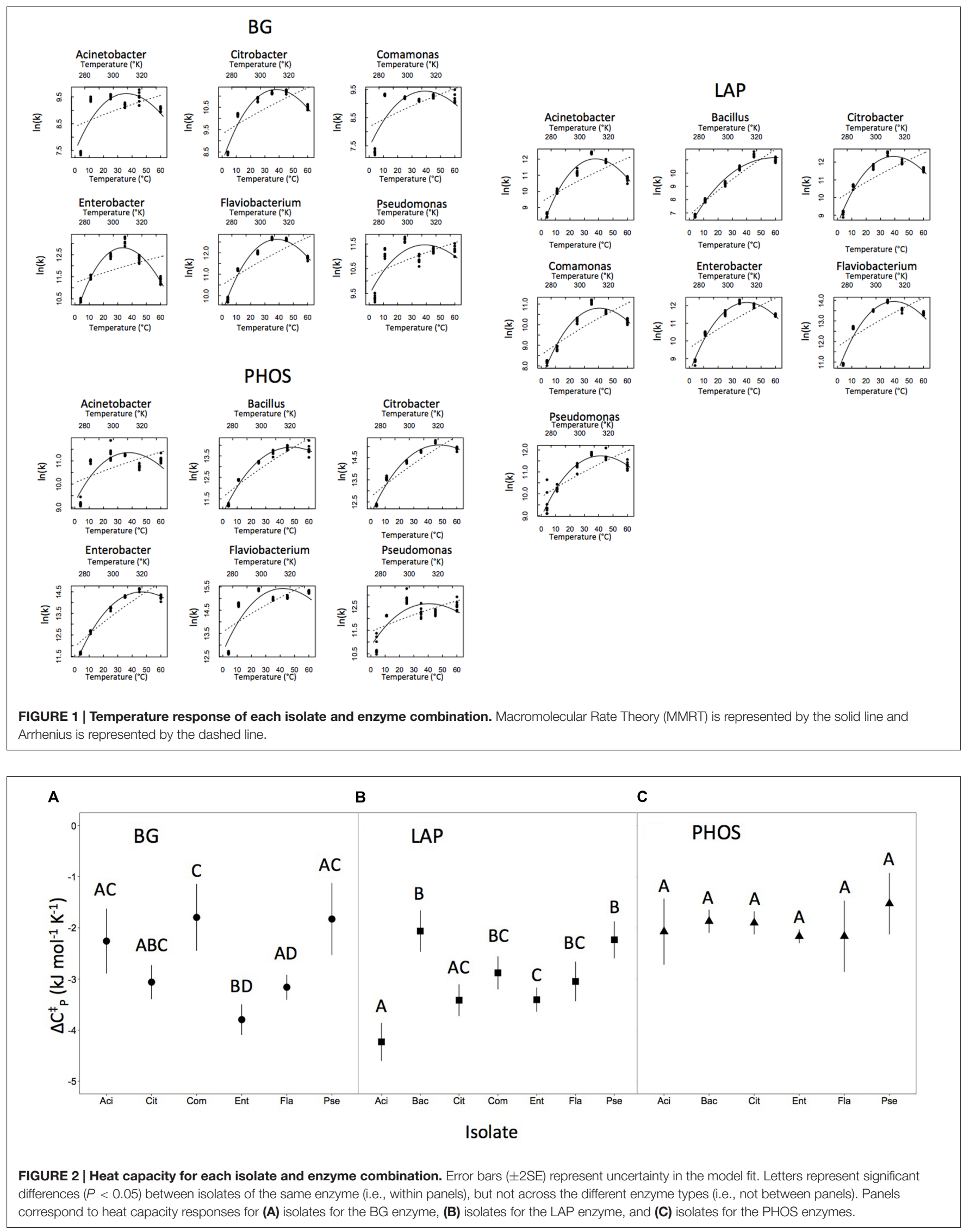
TABLE 1 | Mean temperature optima $\left(T_{\text {opt }}\right)$ and point of maximum temperature sensitivity $\left(T S_{\text {max }}\right)$ for each isolate and enzyme combination \pm SEM.

\begin{tabular}{|c|c|c|c|c|c|c|c|c|}
\hline & \multicolumn{2}{|c|}{ BG } & \multicolumn{2}{|c|}{ LAP } & \multicolumn{2}{|c|}{ PHOS } & \multicolumn{2}{|c|}{ Pooled estimate } \\
\hline & $T_{\text {opt }}$ & $\mathrm{TS}_{\max }$ & $T_{\text {opt }}$ & $\mathrm{TS}_{\max }$ & $T_{\text {opt }}$ & $\mathrm{TS}_{\max }$ & $T_{\text {opt }}$ & $\mathrm{TS}_{\max }$ \\
\hline Acinetobacter & $36.0 \pm 1.9$ & $18.2 \pm 2.4$ & $37.7 \pm 0.6$ & $24.45 \pm 0.6$ & $37.55 \pm 2.1$ & $18.85 \pm 2.6$ & $37.1 \pm 2.9$ & $20.5 \pm 3.6$ \\
\hline Bacillus & NA & NA & $60.7 \pm 2.5$ & $40.25 \pm 1.5$ & $48.05 \pm 1$ & $27.95 \pm 0.7$ & $54.2 \pm 3.3$ & $34.1 \pm 3.0$ \\
\hline Citrobacter & $38.1 \pm 0.7$ & $22.6 \pm 0.8$ & $39.7 \pm 0.6$ & $24.55 \pm 0.6$ & $47.95 \pm 0.9$ & $27.95 \pm 0.7$ & $41.7 \pm 1.3$ & $25.0 \pm 1.2$ \\
\hline Comamonas & $39.1 \pm 2.5$ & $19.0 \pm 3.1$ & $40.6 \pm 0.7$ & $24.55 \pm 0.8$ & NA & NA & $39.8 \pm 2.6$ & $21.8 \pm 3.2$ \\
\hline Enterobacter & $33.5 \pm 0.6$ & $19.8 \pm 0.7$ & $40.0 \pm 0.4$ & $25.25 \pm 0.5$ & $46.85 \pm 0.5$ & $28.25 \pm 0.4$ & $40.1 \pm 0.9$ & $24.4 \pm 0.9$ \\
\hline Flaviobacter & $38.4 \pm 0.5$ & $23.2 \pm 0.6$ & $39.4 \pm 0.8$ & $23.85 \pm 0.9$ & $41.85 \pm 2.2$ & $23.25 \pm 2.3$ & $39.9 \pm 2.4$ & $23.4 \pm 2.5$ \\
\hline Pseudomonas & $39.0 \pm 2.6$ & $19.1 \pm 3.2$ & $41.4 \pm 1.1$ & $23.25 \pm 1.1$ & $40.45 \pm 2.7$ & $18.55 \pm 3.1$ & $40.3 \pm 3.9$ & $20.3 \pm 4.6$ \\
\hline Pooled estimate & $37.3 \pm 4.2$ & $20.3 \pm 5.2$ & $42.6 \pm 3.1$ & $26.6 \pm 2.4$ & $43.8 \pm 4.3$ & $24.1 \pm 4.8$ & - & - \\
\hline
\end{tabular}

Pooled estimates are averages either across enzymes for a given isolate or across isolates for a given enzyme.

significant difference in percent error between MMRT and the Arrhenius $4-35^{\circ} \mathrm{C}$ model fits when compared to original activity values at $4,11,25$, and $35^{\circ} \mathrm{C}$.

\section{Comparison of Activation Energy Values}

To examine the value of using activation energy as a trait, we compared activation energies derived from different temperature ranges to see if they vary. In a 3-way ANOVA examining the $E_{\mathrm{A}}$ values from all three of the Arrhenius model temperature ranges tested, we found that the temperature range explained $68.5 \%$ of variation in the data, compared to $12.7 \%$ explained by enzyme type and $11.0 \%$ explained by isolate type. Overall, we found that as the temperature range increased $E_{\mathrm{A}}$ values decreased (Figures 3B-D). Not only did the absolute values of $E_{\mathrm{A}}$ vary based on temperature range, but the relative $E_{\mathrm{A}}$ values also differ (Figures 3B-D) leading to different groupings of similarity among assays. In comparisons of $E_{\mathrm{A}}$ values for the different inocula $\times$ enzyme combinations that shared either the same enzyme or same isolate, $25 \%$ of the relationships changed between the Arrhenius $4-25$ and $4-35^{\circ} \mathrm{C}$ estimates, and $36.8 \%$ of the relationships changed between the Arrhenius 435 and $4-60^{\circ} \mathrm{C}$ estimates. A similar analysis capturing different temperature ranges was not needed for MMRT since MMRT captures the peak.

\section{DISCUSSION}

\section{Heat Capacity Differs Significantly among Enzymes}

This study advances efforts to understand how temperature sensitivity of extracellular enzymes varies by substrate and isolate type. Such an effect has long been speculated, based on assays conducted at the community level with whole soils (e.g., Trasar-Cepeda et al., 2007; Steinweg et al., 2013). We found that $\Delta C_{\mathrm{p}}^{\ddagger}$ differed significantly among isolates for the BG and LAP enzymes, across the different isolates measured (Figure 2). Furthermore, heat capacity of different enzymes varied within the same isolate for three out of the seven isolates measured. While this study was not designed to elucidate the mechanisms behind why heat capacity varied between some enzymes and isolates but not others, here we provide a few possible explanations. One broad explanation for why we see these differences is that microbes adapt to their environment and more efficient enzymes are selected for in accordance to the thermodynamic conditions in that environment (Bradford, 2013); thus, microbes will adapt to produce isoenzymes with varying degrees of flexibility and consequently different heat capacities values depending on what is most advantageous for the microbial cell's survival. The idea that isoenzymes have distinct temperature sensitivities is not particularly groundbreaking if comparing enzymes derived from thermophilic, psychrophilic, and mesophilic conditions (Zavodszky et al., 1998; Lonhienne et al., 2000; Feller and Gerday, 2003) or even across the same soil microbial community throughout seasons (Koch et al., 2007; Trasar-Cepeda et al., 2007; Wallenstein et al., 2009). However, in this study all of the isolates measured were derived from a mesophilic environment and raised in culture at the same temperature $\left(25^{\circ} \mathrm{C}\right)$. Thus, we found that temperature sensitivity varies even among organisms raised under the same temperature conditions.

In contrast to BG and LAP, the heat capacity of PHOS was invariant with isolate type, suggesting that perhaps this enzyme did not undergo a similar type of adaptation over evolutionary history or that there are simply fewer isoenzymes. Although the PHOS enzyme is ubiquitous across different types of organisms, the genomic region encoding for the active site is highly conserved and fairly homologous across plants, animals, and bacteria, at least for the acidic version of the enzyme (Anand and Srivastava, 2012). As opposed to aminopeptidases in which relatively few homologies have been observed despite their high abundance (Taylor, 1993), gene conservation of PHOS might explain the lack of variation in heat capacity. Thermodynamic constraints of the enzyme or active site may also limit adaptation if there is a fundamental evolutionary tradeoff between the structure and function of the enzyme that is specific to the catalytic properties of PHOS (Bradford, 2013).

It is also worth noting that because these estimates of heat capacity were not necessarily of individual enzymes, but of the all of the isoenzymes produced by the isolates under the incubation conditions of this experiment. While it is unclear if multiple enzymes acting on the substrate impacted the results, it is worth highlighting that these results might be the average of one or more isoenzymes. It is also possible that given our sample size 
A

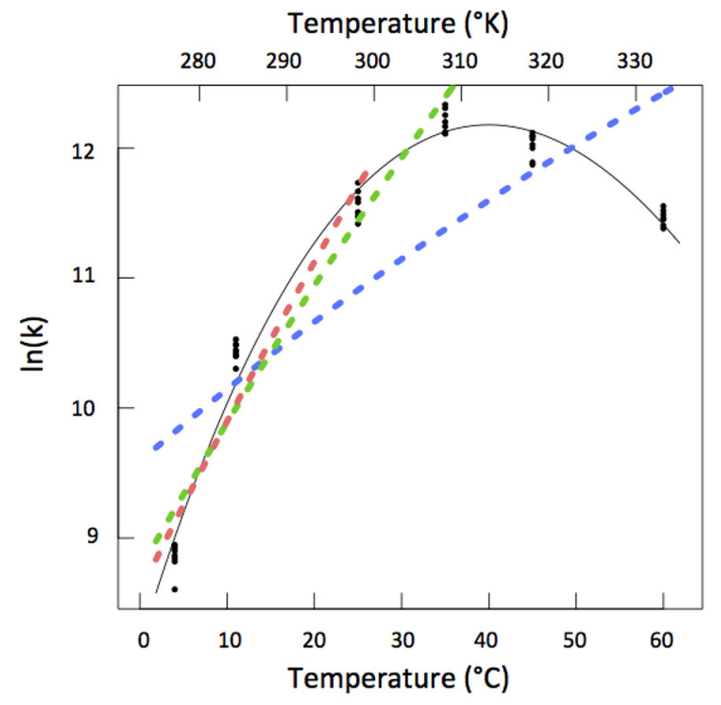

C

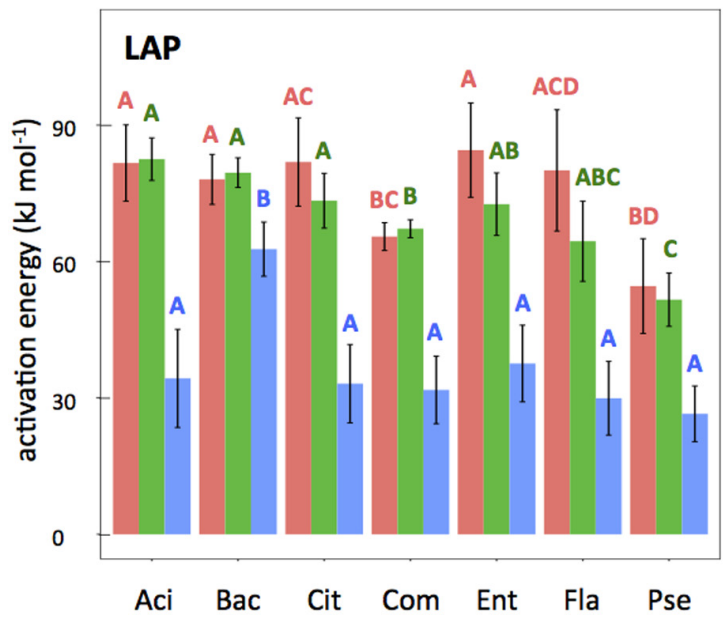

B
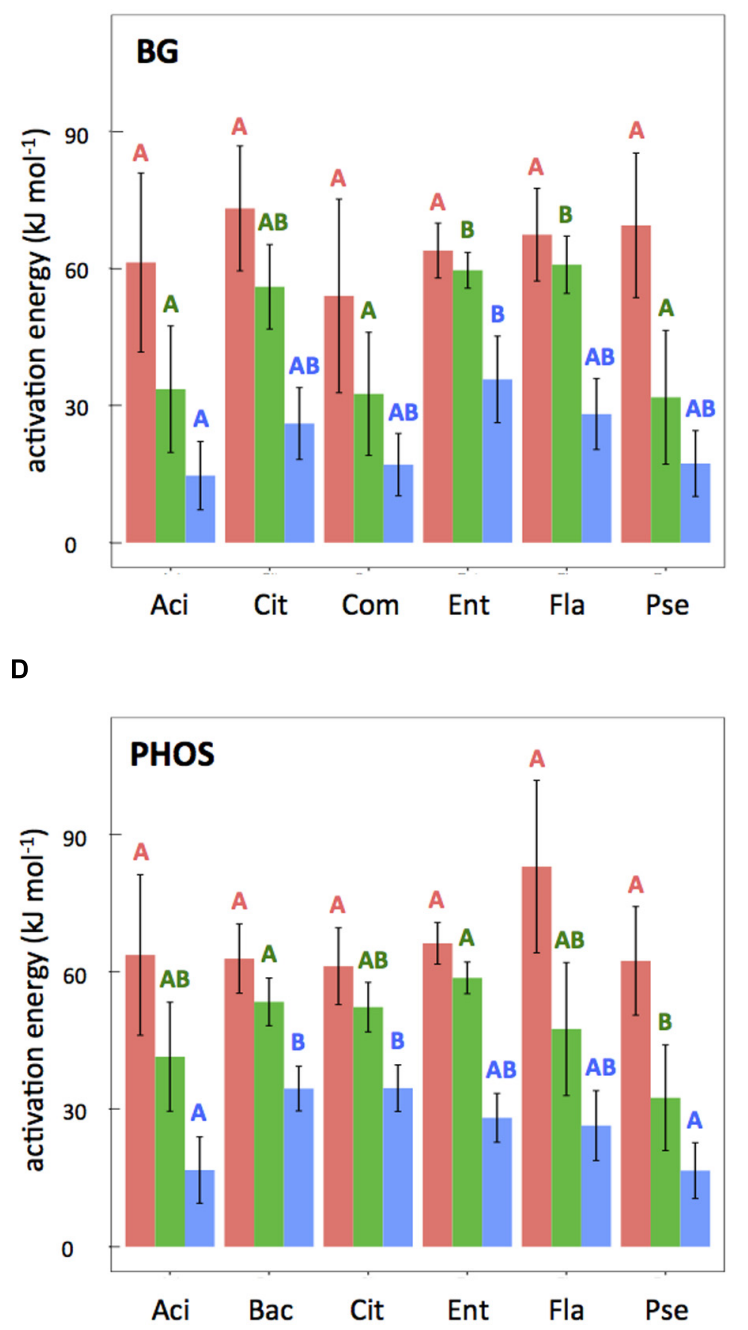

FIGURE 3 | (A) Example temperature response plot (LAP for Enterobacter) showing fits for MMRT, Arrhenius with temperature range $4-60^{\circ} \mathrm{C}$ (blue, dashed line), Arrhenius with temperature range $4-35^{\circ} \mathrm{C}$ (green, dashed line), and Arrhenius with temperature range $4-25^{\circ} \mathrm{C}$ (pink, dashed line). (B-D) Activation energy estimates from the three Arrhenius fits with bars corresponding to Arrhenius $4-25^{\circ} \mathrm{C}$ (pink), Arrhenius $4-35^{\circ} \mathrm{C}$ (green), and Arrhenius with temperature range $4-60^{\circ} \mathrm{C}(\mathrm{blue})$. Error bars $( \pm 2 \mathrm{SE})$ represent uncertainty in the model fit. Letters represent significant differences $(P<0.05)$ between different isolates for the same Arrhenius fit (i.e., $4-25$, 4-35, or $4-60^{\circ} \mathrm{C}$, not between different fits for the same isolate) and within the same enzyme types (i.e., not between panels). Only compare same colors within the same panels.

(seven isolates and three enzymes), more differences in heat capacity may have been observed if we had increased the diversity and number of the isolates and enzymes in the experiment. Furthermore, specific experimental conditions, such as $\mathrm{pH}$, could potentially alter the temperature-response curve. Determining how heat capacity varies phylogenetically for different enzymes is an important avenue for future research.

\section{Exercising Caution for Arrhenius Estimates of Temperature Sensitivity}

Despite clear evidence of MMRT's statistical superiority to Arrhenius in this experiment, we found that at the lower temperature ranges (i.e., $4-25$ and $4-35^{\circ} \mathrm{C}$ ) Arrhenius estimations were not necessarily poor. However, we still recommend that future estimations of temperature sensitivity for soil microbial enzymes that apply the Arrhenius equation use caution for the following reasons. First, we found that $E_{\mathrm{A}}$ values varied significantly with the range in which they were evaluated, making them an unreliable metric to use for comparisons across studies. These results are corroborated by Pawar et al. (2016), who tested 1,085 temperature-response curves from a variety of organisms and systems and determined that the calculated $E_{\mathrm{A}}$ value is an artifact of the temperature range, spread of temperatures measured, and where the temperature range falls. In order for temperature sensitivity to be used as a common currency of discussion and incorporated as a 


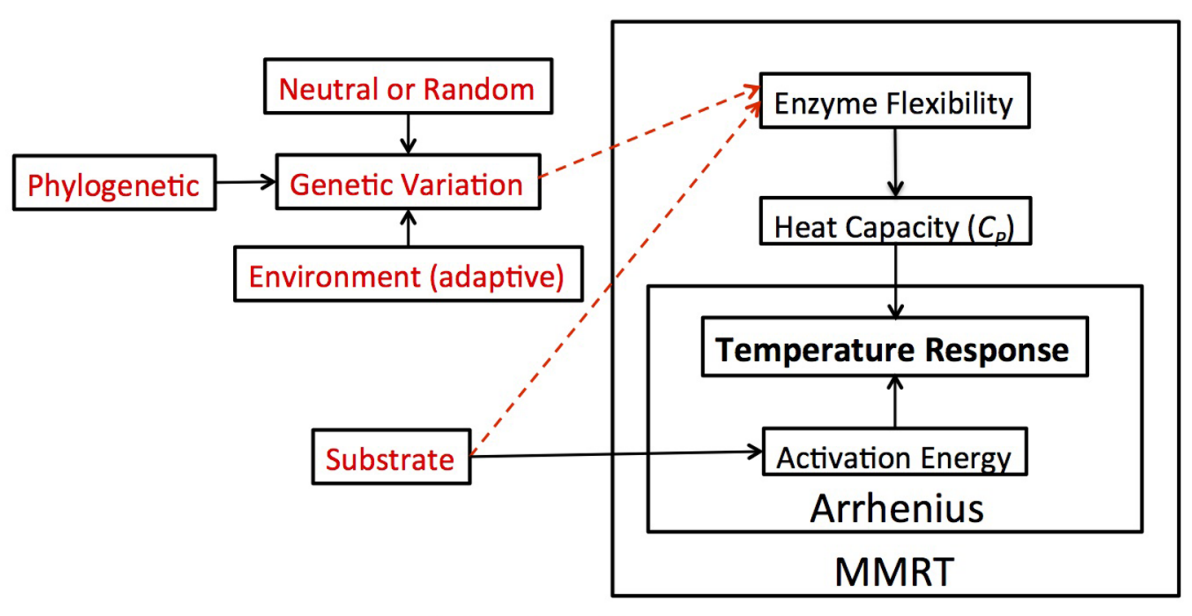

\section{Extended Framework}

FIGURE 4 | Theoretical framework and hypotheses. In this figure, we demonstrate how the Arrhenius and MMRT frameworks fit together conceptually and how that impacts our view of the temperature response, which in our case refers to the reaction rate of extracellular enzymes. Under the Arrhenius framework, activation energy is the singular factor driving the apparent temperature response. MMRT expands upon this framework, suggesting that the temperature response is a function of the heat capacity of an enzyme, which is related to the enzyme's flexibility. While there is already evidence for substrate type influencing activation energy (solid arrow connecting substrate to activation energy), in this experiment (red lettering) we extend this framework and hypothesize that the enzyme flexibility is also a product of the substrate type and genetic variation among different enzymes (dashed arrows). We posit that this overarching framework could be applied in a variety of situations relating to the temperature response.

microbial trait, relationships should not be a function of different measurement methods. Second, even if Arrhenius is comparable to MMRT in a narrow temperature range, $E_{\mathrm{A}}$ fails to capture key phenomenological features of temperature sensitivity in soil biological systems. Other non-linear models have also been shown to give suitable empirical fits to the temperature dependence of enzyme activity (Peterson et al., 2004; Del Grosso et al., 2005; Daniel and Danson, 2013; Corkrey et al., 2014), but MMRT not only fits well empirically, but is derived from thermodynamic theory and thus has an underlying theoretical basis. Thus, even if $E_{\mathrm{A}}$ continues to be used in the future, $E_{\mathrm{A}}$ values should not be taken as true indicators of temperature sensitivity, at least for soil extracellular enzymes.

\section{Conceptual Framework}

For nearly a decade, scientists have recognized the importance of using microbial traits as a framework for predicting ecosystem response to climate change (Green et al., 2008; Wallenstein and Hall, 2012). Many of these studies make predictions about how microbial traits (e.g., nutrient use efficiency) respond across a gradient of temperatures (Rinnan et al., 2009; Dell et al., 2011; Wallenstein and Hall, 2012). In this study we argue that temperature sensitivity is not only a measure of how biological traits respond across a gradient of temperatures, which is how it is typically characterized, but also that temperature sensitivity is an inherent biological trait. In light of this interest and our results, we developed a new conceptual model that develops a more precise definition of temperature sensitivity and organizes the factors that can lead to variation in temperature sensitivity itself.
In our framework, we first consolidated the Arrhenius and MMRT definitions of temperature sensitivity. Under the Arrhenius equations, activation energy is the singular factor driving the apparent temperature response (Figure 4). But, this violates laws of thermodynamics with regards to biological systems because of the large molecular size of enzymes characterized by large heat capacities impacting the temperature response (Arcus et al., 2016). MMRT expands thermodynamic theory initiated with Arrhenius by incorporating heat capacity as part of the temperature response (Figure 4). Implicit within the MMRT theory is that the $\Delta C_{\mathrm{p}}^{\ddagger}$ is a function of enzyme flexibility and thus $\Delta C_{\mathrm{p}}^{\ddagger}$ varies among enzymes (Schulte, 2015; Arcus et al., 2016). Given existing evidence for substrate type influencing activation energy (Davidson and Janssens, 2006), our outline of temperature sensitivity includes potential for enzyme flexibility to be a product of the substrate upon which the enzyme acts as well as the genetic variation among different enzymes (Figure 4). In this experiment, we tested if these additional factors (i.e., substrate type and genetic variation) impacted the temperature sensitivity by measuring heat capacity as a proxy for enzyme flexibility and found strong evidence for heat capacity varying by both enzyme and isolate type.

Based on this expanded framework of temperature sensitivity, we propose that use of $\Delta C_{\mathrm{p}}^{\ddagger}$ and $\mathrm{TS}_{\max }$ will give a more comprehensive basis to describe "temperature sensitivity" than $Q_{10}$ or $E_{\mathrm{A}}$. $Q_{10}$ gives a false sense that a single constant can characterize the temperature sensitivity of a system (Davidson and Janssens, 2006). In order to overcome this obvious discrepancy authors using $Q_{10}$ often present multiple temperature sensitivity values at different temperature ranges for a given system, leading to results that are often difficult to 
compare. Conceptually, we consider temperature sensitivity to be the change in velocity per change in temperature $(d V / d T)$. Unlike $Q_{10}, E_{\mathrm{A}}$ can be used as a summary term to capture temperature sensitivity of a system; this is effective because Arrhenius predicts a monotonic increase in rate with temperature. Since MMRT captures the inherently non-monotonic response of enzymecatalyzed reactions, a single variable cannot fully capture the temperature sensitivity from the MMRT curve as is done by $E_{\mathrm{A}}$ in the Arrhenius equation. Thus the use of $\mathrm{TS}_{\max }$ and $T_{\text {opt }}$ provide two practical metrics to characterize this non-linear response of temperature sensitivity to temperature, although for modeling purposes $\Delta C_{\mathrm{p}}^{\ddagger}$ and other thermodynamic parameters (i.e., $\Delta S_{T_{0}}^{\ddagger}$ and $\Delta H_{T_{0}}^{\ddagger}$ ) are sufficient to explicitly predict reaction rates with temperature. Temperature optimum values are also commonly reported in the literature for extracellular enzymes (Huston et al., 2000; Daniel et al., 2001; Peterson et al., 2004; Eijsink et al., 2005), but are typically quite high and perhaps not biologically relevant. We argue that $\mathrm{TS}_{\max }$ is actually a more important term to consider than $T_{\text {opt }}$ because $\mathrm{TS}_{\max }$ describes where the greatest change in rate occurs and it typically falls within environmentally relevant temperature ranges (Table 1). Consequently, by focusing on $\mathrm{TS}_{\max }$ we capture the area of the temperature-reaction curve that will have the greatest impact on rates of nutrient cycling and greenhouse gas production. Characterizing temperature sensitivity with these unifying parameters gives us an avenue to incorporate temperature sensitivity into traits-based microbial models.

Our new framework suggests a number of future lines of inquiry. One immediate question is: how broadly does temperature sensitivity vary under this new definition of temperature sensitivity? If temperature sensitivity of different

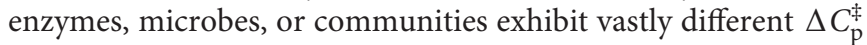
and $\mathrm{TS}_{\max }$ values then this might impact current calculations of soil $\mathrm{C}$ and $\mathrm{N}$ dynamics. As the climate warms, does this inherent temperature sensitivity adapt or acclimate? What are the evolutionary constraints on rate of evolution and how is the overall temperature sensitivity value impacting by different groups of organisms? What other factors besides enzyme type and the microbe from which it was produced might impact enzyme flexibility? We hope that future research will be conducted in many of these avenues to elucidate mechanisms controlling

\section{REFERENCES}

Allison, S. D., Weintraub, M. N., Gartner, T. B., and Waldrop, M. P. (2011). "Evolutionary-economic principles as regulators of soil enzyme production and ecosystem function," in Soil Enzymology, eds G. Shukla and A. Varma (Berlin: Springer), 229-243.

Alster, C. J., Koyama, A., Johnson, N. G., Wallenstein, M. D., and Fischer, J. C. (2016). Temperature sensitivity of soil microbial communities: an application of macromolecular rate theory to microbial respiration. J. Geophys. Res. 121, 1420-1433. doi: 10.1002/2016JG 003343

Anand, A., and Srivastava, P. K. (2012). A molecular description of acid phosphatase. Appl. Biochem. Biotechnol. 167, 2174-2197. doi: 10.1007/s12010012-9694-8

Arcus, V. L., Prentice, E. J., Hobbs, J. K., Mulholland, A. J., van der Kamp, M. W., Pudney, C. R., et al. (2016). On the temperature dependence of temperature sensitivity of enzymes and determine what impact this has on communities, ecosystems, and nutrient cycling in soils.

\section{AUTHOR CONTRIBUTIONS}

$\mathrm{CA}, \mathrm{JvF}, \mathrm{PB}$, and MW developed the original concepts. CA and $\mathrm{PB}$ designed and performed the experiments. MW and CA contributed materials. CA conducted data analysis with significant involvement from $\mathrm{JvF}$ and NJ. CA wrote the manuscript with help from JvF, PB, MW, and NJ.

\section{FUNDING}

This work was supported by NSF grant 1054956 and a grant from the Environmental Defense Fund to JvF, USDA NIFA grant 201405626 to MW, and the Graduate Degree Program in Ecology at Colorado State University Small Grants for Graduate Research. The National Institute for Mathematical and Biological Synthesis is an Institute sponsored by the National Science Foundation through NSF Award \#DBI-1300426, with additional support from The University of Tennessee, Knoxville.

\section{ACKNOWLEDGMENTS}

We would like to thank Lauren Mancini for her laboratory help, and Vickery Arcus and Louis Schipper for their help with the MMRT model, and M. Francesca Cotrufo, Melinda Smith, and the two reviewers. We wish to thank Ann Hess at the Franklin Graybill Statistical Laboratory at Colorado State University for statistical consulting help.

\section{SUPPLEMENTARY MATERIAL}

The Supplementary Material for this article can be found online at: http://journal.frontiersin.org/article/10.3389/fmicb. 2016.01821/full\#supplementary-material

enzyme-catalyzed rates. Biochemistry 55, 1681-1688. doi: 10.1021/acs.biochem. 5 b01094

Bell, C. W., Fricks, B. E., Rocca, J. D., Steinweg, J. M., McMahon, S. K., and Wallenstein, M. D. (2013). High-throughput fluorometric measurement of potential soil extracellular enzyme activities. J. Vis. Exp. 2013:e50961. doi: $10.3791 / 50961$

Bradford, M. A. (2013). Thermal adaptation of decomposer communities in warming soils. Front. Microbiol. 4:333. doi: 10.3389/fmicb.2013. 00333

Brzostek, E. R., and Finzi, A. C. (2012). Seasonal variation in the temperature sensitivity of proteolytic enzyme activity in temperate forest soils. J. Geophys. Res. 117, G01018. doi: 10.1029/2011JG001688

Burns, R. G., and Dick, R. P. (2002). Enzymes in the Environment: Activity, Ecology, and Applications. Boca Raton, FL: CRC Press.

Chapin, III. F. S., and Matson, P. A. (2011). Principles of Terrestrial Ecosystem Ecology. Berlin: Springer. 
Corkrey, R., McMeekin, T. A., Bowman, J. P., Ratkowsky, D. A., Olley, J., and Ross, T. (2014). Protein thermodynamics can be predicted directly from biological growth rates. PLoS ONE 9:e96100. doi: 10.1371/journal.pone.0096100

Daniel, R. M., and Danson, M. J. (2013). Temperature and the catalytic activity of enzymes: a fresh understanding. FEBS Lett. 587, 2738-2743. doi: 10.1016/j.febslet.2013.06.027

Daniel, R. M., Danson, M. J., and Eisenthal, R. (2001). The temperature optima of enzymes: a new perspective on an old phenomenon. Trends Biochem. Sci. 26, 223-225. doi: 10.1016/S0968-0004(01)01803-5

Davidson, E. A., and Janssens, I. A. (2006). Temperature sensitivity of soil carbon decomposition and feedbacks to climate change. Nature 440, 165-173. doi: 10.1038/nature 04514

Del Grosso, S. J., Parton, W. J., Mosier, A. R., Holland, E. A., Pendall, E., Schimel, D. S., et al. (2005). Modeling soil CO2 emissions from ecosystems. Biogeochemistry 73, 71-91. doi: 10.1007/s10533-004-0898-z

Dell, A. I., Pawar, S., and Savage, V. M. (2011). Systematic variation in the temperature dependence of physiological and ecological traits. Proc. Natl. Acad. Sci. U.S.A. 108, 10591-10596. doi: 10.1073/pnas.1015178108

Eijsink, V. G. H., Gåseidnes, S., Borchert, T. V., and van den Burg, B. (2005). Directed evolution of enzyme stability. Biomol. Eng. 22, 21-30. doi: 10.1016/j.bioeng.2004.12.003

Elias, M., Wieczorek, G., Rosenne, S., and Tawfik, D. S. (2014). The universality of enzymatic rate-temperature dependency. Trends Biochem. Sci. 39, 1-7. doi: 10.1016/j.tibs.2013.11.001

Feller, G. (2003). Molecular adaptations to cold in psychrophilic enzymes. Cell. Mol. Life Sci. 60, 648-662. doi: 10.1007/s00018-003-2155-3

Feller, G., and Gerday, C. (2003). Psychrophilic enzymes: hot topics in cold adaptation. Nat. Rev. Microbiol. 1, 200-208. doi: 10.1038/nrmicro773

Green, J. L., Bohannan, B. J. M., and Whitaker, R. J. (2008). Microbial biogeography: from taxonomy to traits. Science 320, 1039-1043. doi: 10.1126/science. 1153475

Hobbs, J. K., Jiao, W., Easter, A. D., Parker, E. J., Schipper, L. A., and Arcus, V. L. (2013). Change in heat capacity for enzyme catalysis determines temperature dependence of enzyme catalyzed rates. ACS Chem. Biol. 8, 2388-2393. doi: $10.1021 / \mathrm{cb} 4005029$

Huston, A. L., Krieger-Brockett, B. B., and Deming, J. W. (2000). Remarkably low temperature optima for extracellular enzyme activity from Arctic bacteria and sea ice. Environ. Microbiol. 2, 383-388. doi: 10.1046/j.1462-2920.2000.00118.x

Karhu, K., Auffret, M. D., Dungait, J. A. J., Hopkins, D. W., Prosser, J. I., Singh, B. K., et al. (2014). Temperature sensitivity of soil respiration rates enhanced by microbial community response. Nature 513, 81-84. doi: 10.1038/nature13604

Koch, O., Tscherko, D., and Kandeler, E. (2007). Temperature sensitivity of microbial respiration, nitrogen mineralization, and potential soil enzyme activities in organic alpine soils. Glob. Biogeochem. Cycles 21, GB4017. doi: 10.1029/2007GB002983

Kuznetsova, A., Brockhoff, P. B., and Christensen, R. H. B. (2014). lmerTest: Tests for Random and Fixed Effects for Linear Mixed Effect Models (lmer Objects of lme4 package). R package version 2.0-11. Available at: http://CRAN.R-project. org/package $=$ lmerTest

Lloyd, J., and Taylor, J. A. (1994). On the temperature dependence of soil respiration. Funct. Ecol. 8, 315-323. doi: 10.2307/2389824

Lonhienne, T., Gerday, C., and Feller, G. (2000). Psychrophilic enzymes: revisiting the thermodynamic parameters of activation may explain local flexibility. Biochim. Biophys. Acta 1543, 1-10. doi: 10.1016/S0167-4838(00)00210-7

McGill, B. J., Enquist, B. J., Weiher, E., and Westoby, M. (2006). Rebuilding community ecology from functional traits. Trends Ecol. Evol. 21, 178-185. doi: 10.1016/j.tree.2006.02.002

Pawar, S., Dell, A. I., Savage, V. M., Knies, J. L., Kearney, M., and Kalisz, S. (2016). Real versus artificial variation in the thermal sensitivity of biological traits. Am. Nat. 187, E41-E52. doi: 10.1086/684590
Peterson, M. E., Eisenthal, R., Danson, M. J., Spence, A., and Daniel, R. M. (2004). A new intrinsic thermal parameter for enzymes reveals true temperature optima. J. Biol. Chem. 279, 20717-20722. doi: 10.1074/jbc.M309 143200

R Core Team (2015). R: A language and Environment for Statistical Computing. Vienna: R Foundation for Statistical Computing.

Rinnan, R., Rousk, J., Yergeau, E., Kowalchuk, G. A., and Bååth, E. (2009). Temperature adaptation of soil bacterial communities along an Antarctic climate gradient: predicting responses to climate warming. Glob. Change Biol. 15, 2615-2625. doi: 10.1111/j.1365-2486.2009.01959.x

Schipper, L. A., Hobbs, J. K., Rutledge, S., and Arcus, V. L. (2014). Thermodynamic theory explains the temperature optima of soil microbial processes and high Q10 values at low temperatures. Glob. Change Biol. 20, 3578-3586. doi: $10.1111 /$ gcb. 12596

Schulte, P. M. (2015). The effects of temperature on aerobic metabolism: towards a mechanistic understanding of the responses of ectotherms to a changing environment. J. Exp. Biol. 218, 1856-1866. doi: 10.1242/jeb.118851

Sierra, C. A. (2012). Temperature sensitivity of organic matter decomposition in the Arrhenius equation: some theoretical considerations. Biogeochemistry 108, 1-15. doi: 10.1007/s10533-011-9596-9

Steinweg, J. M., Jagadamma, S., Frerichs, J., and Mayes, M. A. (2013). Activation energy of extracellular enzymes in soils from different biomes. PLoS ONE 8:e59943. doi: 10.1371/journal.pone.0059943

Struvay, C., and Feller, G. (2012). Optimization to low temperature activity in psychrophilic enzymes. Int. J. Mol. Sci. 13, 11643-11665. doi: 10.3390/ijms130911643

Taylor, A. (1993). Aminopeptidases: structure and function. FASEB J. 7, 290-298.

Trasar-Cepeda, C., Gil-Sotres, F., and Leirós, M. C. (2007). Thermodynamic parameters of enzymes in grassland soils from Galicia. NW Spain. Soil Biol. Biochem. 39, 311-319. doi: 10.1016/j.soilbio.2006.08.002

Wallenstein, M., Allison, S. D., Ernakovich, J., Steinweg, J. M., and Sinsabaugh, R. (2011). Controls on the temperature sensitivity of soil enzymes: a key driver of in situ enzyme activity rates. Soil Enzymol. 22, 245-258.

Wallenstein, M. D., and Hall, E. K. (2012). A trait-based framework for predicting when and where microbial adaptation to climate change will affect ecosystem functioning. Biogeochemistry 109, 35-47. doi: 10.1007/s10533-0119641-8

Wallenstein, M. D., McMahon, S. K., and Schimel, J. P. (2009). Seasonal variation in enzyme activities and temperature sensitivities in Arctic tundra soils. Glob. Change Biol. 15, 1631-1639. doi: 10.1111/j.1365-2486.2008. 01819.x

Webb, C. T., Hoeting, J. A., Ames, G. M., Pyne, M. I., and LeRoy Poff, N. (2010). A structured and dynamic framework to advance traits-based theory and prediction in ecology. Ecol. Lett. 13, 267-283. doi: 10.1111/j.14610248.2010.01444.x

Zavodszky, P., Kardos, J., Svingor, Á, and Petsko, G. A. (1998). Adjustment of conformational flexibility is a key event in the thermal adaptation of proteins. Proc. Natl. Acad. Sci. U.S.A. 95, 7406-7411. doi: 10.1073/pnas.95.13.7406

Conflict of Interest Statement: The authors declare that the research was conducted in the absence of any commercial or financial relationships that could be construed as a potential conflict of interest.

Copyright (c) 2016 Alster, Baas, Wallenstein, Johnson and von Fischer. This is an open-access article distributed under the terms of the Creative Commons Attribution License (CC BY). The use, distribution or reproduction in other forums is permitted, provided the original author(s) or licensor are credited and that the original publication in this journal is cited, in accordance with accepted academic practice. No use, distribution or reproduction is permitted which does not comply with these terms. 